\title{
Captopril in hypertension after renal transplantation
}

\author{
M. K. CHAN* \\ M.D., M.R.C.P. \\ A. M. El NAHAS \\ M.R.C.P. \\ O. N. FERNANDO \\ F.R.C.S., F.R.C.S.(E.)
}

\author{
P. SWENY \\ M.D., M.R.C.P.
}

K. FARRINGTON

M.R.C.P.

J. F. MOORHEAD

F.R.C.P.

Department of Nephrology and Transplantation, The Royal Free Hospital, Pond Street, London NW3 20G

\begin{abstract}
Summary
Eight hypertensive renal allograft recipients who had received captopril are presented. Captopril in a maximal daily dose of $250 \mathrm{mg}$ enabled the withdrawal of large doses of beta-blocking agents and vasodilators. Blood pressure was satisfactorily controlled in all except one. No adverse side effects were observed other than the 'first dose' effect which resulted in transient anuria in one patient. Captopril appears to be a useful agent in the management of severe hypertension after renal transplantation.
\end{abstract}

KEY WORDS: anuria, thrombocytopenia.

\section{Introduction}

Hypertension is common after renal transplantation and frequently resistant to conventional antihypertensive therapy including the combination of a beta-blocker, a vasodilator and a diuretic. We report here our experience in the use of captopril, an angiotensin-converting-enzyme inhibitor active by the oral route (Vidt, Bravo and Fouad, 1982), in eight renal allograft recipients for up to 15 months.

\section{Patients and methods}

All eight patients had hypertension which could not be adequately controlled by the standard triple therapy, i.e. the combination of a beta-blocker, a vasodilator and a diuretic. A variety of beta-blockers were often tried in the same patient. The vasodilator commonly used was hydralazine. The maximal daily dose of captopril never exceeded $250 \mathrm{mg}$, and was given in two to three divided doses. The diuretic used was frusemide. In three patients, hydralazine had to

\footnotetext{
*Present address: Department of Medicine, University of Hong Kong, Queen Mary Hospital, Hong Kong.
}

be replaced by minoxidil after maximal doses of thi former proved ineffective. In these patients, the bloog pressure was reasonably well controlled but hirsutism became intolerable and the patients were switched 8 captopril. None of the patients had bilateral nephre tomy either before or after renal transplantation. initial test dose of $25 \mathrm{mg}$ was given in all but on patient who received $6.25 \mathrm{mg}$. The initial dose effect (i.e. decrease in blood pressure within $2 \mathrm{hr}$ ) apparent in all patients, but in only one of themsias hypotension so severe that it resulted in transieg anuria. The dose of captopril was adjusted accordin to the control of blood pressure and was increased weekly or monthly intervals to a maximal dose of 25 $\mathrm{mg}$ daily. All patients were maintained on diuretie therapy before and throughout the period of trea $\vec{F}$ ment with captopril. The patients were seen week and later monthly. Blood pressure was measured bif mercury sphygmomanometer. At every visit, blood was taken for haematological tests, liver function and renal function tests and proteinuria was determinea in $24 \mathrm{hr}$ urine samples. The clinical and laborator data of the patients are summarized in Table 1 and Fig. 1.

\section{Results}

Good blood pressure control was achieved in except one patient, D.C., who had severe arterialf stenosis of the transplant kidney which had failed respond to transluminal balloon-catheter dilatation The patient also had relentless vascular rejections and the allograft had to be removed 3 months aftet starting captopril. Patient M.K. had accelerated hypertension when she presented with renal failure. Her blood pressure was controlled with captoprif while she was on continuous ambulatory peritoneal dialysis. She again became hypertensive shortly aftef 


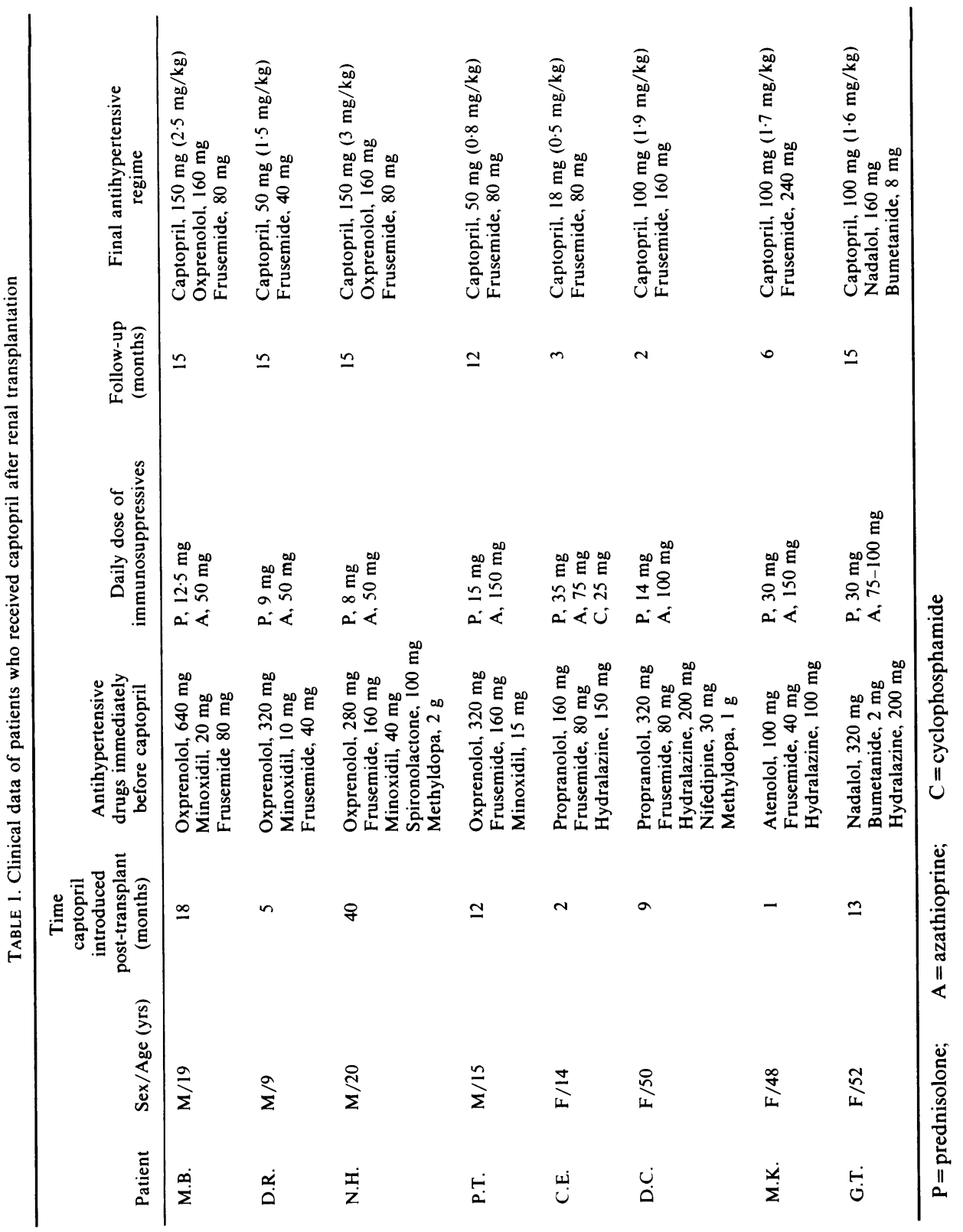




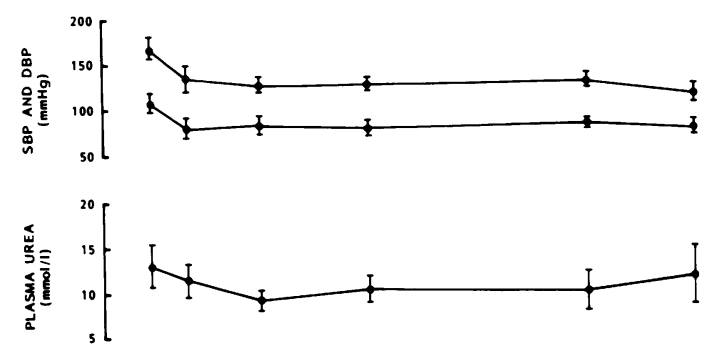

patients who were treated with captopril because of hypertension after renal transplantation have beeß reported (Elijovisch and Krakoff, 1980; Aurell, Delifn and Herlitz, 1980; Kirchertz et al., 1981, Hamilton $\vec{e}$ al., 1981). One patient who received $450 \mathrm{mg}$ of captopril daily had granulocytopenia (Elijovisch and Krakoff, 1980). The fact that no leucopenic episod $\frac{\stackrel{F}{\not}}{2}$ were experienced although all our patients receive azathioprine and captopril concurrently must be related to the small dose of captopril used. Tho average dose was $89 \mathrm{mg}$ daily, whereas the doses useft in patients who developed severe leucopenia and agranulocytosis often exceeded $200 \mathrm{mg}$ daily (Vidt $\overrightarrow{e b}$ al., 1982). No proteinuria occurred de novo in ou patients. Indeed as the blood pressure came under control and renal function improved, proteinurit. frequently subsided. No clinical or biochemica evidence of hepatotoxicity due to captopril wais detected in our study.

We conclude that captopril is extremely useful $\overrightarrow{\mathrm{i}}$ the treatment of severe hypertension after renâ transplantation. Recognizing the potential additive effects of azathioprine and captopril (Kirchertz et al 1981), we have not ventured beyond a maximal daikg dose of $250 \mathrm{mg}$. Since the first dose effect can be very dramatic as was evident in one patient who has transient hypotension and anuria, patients are best admitted into hospital for observation at the confo mencement of captopril therapy. Captopril is maifly excreted in the kidney (Vidt et al., 1982) and the cose must be appropriately adjusted according to the ren function. With more experience, it may even prove the drug of choice since many hypertensive ren allograft recipients have high plasma renin activitie

FIG. 1. Change in clinical and biochemical parameters after represent the mean values and the vertical bars the s.e.m. In parenthesis are the numbers of patients receiving captopril.

renal transplantation and captopril was re-introduced after a short trial of beta-blockers and hydralazine. Patient G.T. who had chronic vascular rejection and whose blood pressure initially proved resistant to captopril had transient episodes of mild thrombocytopenia (platelet count $70 \times 10 /$ litre) which reverted to normal when the dose of azathioprine was reduced. Her platelet count 15 months after commencement of captopril was $135 \times 10 /$ litre. Captopril was reduced from a maximal dose of $250 \mathrm{mg}$ to 100 $\mathrm{mg}$ daily. Haematological indices, liver function tests and plasma urate did not show any consistent trend.

Mean $24 \mathrm{hr}$ urinary protein excretion was $0.86 \mathrm{~g}$ when captopril was started, but fell to $0.08 \mathrm{~g}$ after 12 weeks of treatment. No proteinuria was detected after either 12 or 15 months of captopril.

\section{Discussion}

Early reports of leucopenia/agranulocytosis in patients treated with captopril must have caused great anxiety and concern over the use of this drug in hypertensive renal allograft recipients. Only 16

\section{References}

Aurell, M., Delin, K. \& Herlitz, H. (1980) Short- and long-ter? captopril treatment in severe hypertension, Abstracts EDTA, 17,3.

EluovisCH, F. \& KRAKOFF, L.R. (1980) Captopril-associated granulocytopenia in hypertension after renal transplantation. Lancet, i, 927.

Hamilton, D.V., Evans, D.B., Maidment, G. \& PRYoR, I.S. (198苗) Captopril for refractory hypertension in patients with chronic renal failure and renal transplantation. Journal of the Roge Society of Medicine, 74, 357.

KirchertZ, E.J., Grone, H.J., Rieger, J., Holscher, M. 8 SCHELEV, F. (1981) Successful low dose captopril rechallengt following drug-induced leucopenia. Lancet, i, 1362.

VIDT, D.G., BRAVO, E.L. \& FouAD, F.M. (1982) Medical intel gence, drug therapy: Captopril. New England Journal of Medicing 306, 214.

(Accepted 21 April 1983) 